
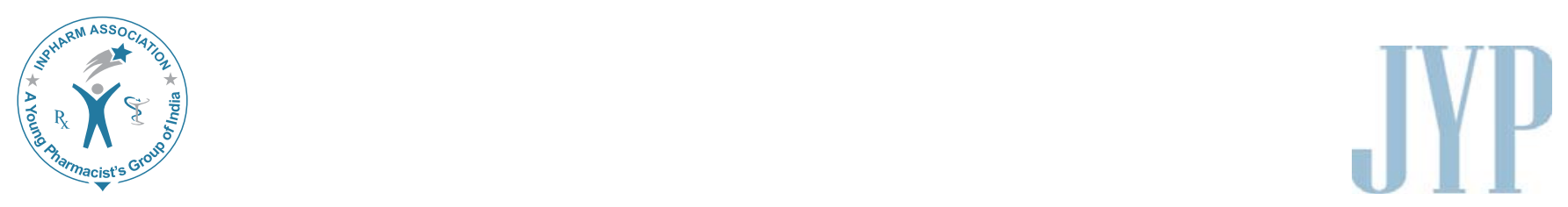

\title{
Formulation and in vitro evaluation of floating tablets of hydroxypropyl methylcellulose and polyethylene oxide using ranitidine hydrochloride as a model drug
}

\author{
Gharti KP, Thapa $\mathrm{P}^{1}$, Budhathoki U, Bhargava $\mathrm{A}^{2}$ \\ Department of Pharmacy, Institute of Medicine, Maharajgunj, Kathmandu, ${ }^{1}$ Department of Pharmacy, \\ Kathmandu University, Dhulikhel, Kavre, Nepal, ${ }^{2}$ Ranbaxy Research Labs, \\ Udhyog Vihar, Gurgaon, Haryana, India \\ Address for correspondence: Mr. Kul P. Gharti,E-mail: phr.kul@gmail.com
}

\begin{abstract}
The present study was carried out with an objective of preparation and in vitro evaluation of floating tablets of hydroxypropyl methyl cellulose (HPMC) and polyethylene oxide (PEO) using ranitidine hydrochloride as a model drug. The floating tablets were based on effervescent approach using sodium bicarbonate a gas generating agent. The tablets were prepared by dry granulation method. The effect of polymers concentration and viscosity grades of HPMC on drug release profile was evaluated. The effect of sodium bicarbonate and stearic acid on drug release profile and floating properties were also investigated. The result of in vitro dissolution study showed that the drug release profile could be sustained by increasing the concentration of HPMC K15MCR and Polyox WSR303. The formulation containing HPMC K15MCR and Polyox WSR303 at the concentration of $13.88 \%$ showed $91.2 \%$ drug release at the end of 24 hours. Changing the viscosity grade of HPMC from K15MCR to K100MCR had no significant effect on drug release profile. Sodium bicarbonate and stearic acid in combination showed no significant effect on drug release profile. The formulations containing sodium bicarbonate $20 \mathrm{mg}$ per tablet showed desired buoyancy (floating lag time of about 2 minutes and total floating time of $>24$ hours). The present study shows that polymers like HPMC K15MCR and Polyox WSR303 in combination with sodium bicarbonate as a gas generating agent can be used to develop sustained release floating tablets of ranitidine hydrochloride.
\end{abstract}

Key words: Floating drug delivery system, gastroretentive drug delivery system, HPMC, PEO, ranitidine hydrochloride, sustained release

\section{INTRODUCTION}

Gastroretentive drug delivery systems are designed to be

\begin{tabular}{|l|l|}
\hline \multicolumn{2}{|c|}{ Access this article online } \\
\hline Quick Response Code: & \\
\hline & Website: \\
\hline & www.jyoungpharm.in \\
& DOI: \\
\hline
\end{tabular}

retained in the stomach for a prolonged time and release their active ingredients and thereby enable sustained and prolonged input of the drug to the upper part of the gastrointestinal tract. ${ }^{[1]}$ A modified release drug delivery system with prolonged residence time in the stomach is of particular interest for drugs- acting locally in the stomach; having an absorption window in the stomach or in the upper part of small intestine; those unstable in the intestinal or colonic environments; or those having low solubility at high $\mathrm{pH}$ values. ${ }^{[2]}$ 
To formulate a successful gastroretentive drug delivery system, several techniques are currently used such as floating drug delivery system, low density systems, raft systems incorporating alginate gel, bioadhesive or mucoadhesive systems, high density systems, superporous hydrogel and magnetic system. Among these, the floating dosage forms have been most commonly used. ${ }^{[3]}$

Floating drug delivery systems have a bulk density less than gastric fluids and so remain buoyant in the stomach without affecting the gastric emptying rate for a prolonged period of time. While the system is floating on the gastric contents, the drug is released slowly at the desired rate from the system. After release of drug, the residual system is emptied from the stomach. This results in an increased gastric retention time and control of the fluctuation in plasma drug concentration. ${ }^{[4]}$

Ranitidine hydrochloride is a histamine $\mathrm{H}_{2}$ - receptor antagonist widely prescribed in active duodenal ulcers, gastric ulcers, Zollinger- Ellison syndrome, Helicobacter pylori eradication, gastro esophageal reflux disease and erosive esophagitis. The recommended adult oral dose of ranitidine for duodenal ulcer, gastric ulcer and gastroesophageal reflux disease is $150 \mathrm{mg}$ twice daily. ${ }^{[5]}$ The patient suffering with erosive esophagitis is effectively treated by administration of $150 \mathrm{mg}$ of ranitidine four times a day. However, the four times a day dosing regimen often tends to poor patient compliance. Studies have shown that patient compliance increases as the dosing regimen goes from four times a day to twice or once a day. Therefore, a dosage form that reduces the ranitidine daily dosing regimen, while maintaining a stable plasma level of ranitidine i.e. a sustained release form, would be advantageous. ${ }^{[6]}$

A traditional oral sustained release formulation releases most of the drug at the colon. Thus it is suitable only for the drugs having absorption window either in the colon or throughout the gastrointestinal tract. Ranitidine has $50 \%$ absolute bioavailability, and it is only absorbed in the initial part of the small intestine. ${ }^{[7]}$ Moreover, colonic metabolism of ranitidine is partly responsible for the poor bioavailability of ranitidine from the colon. ${ }^{[8]}$ These properties of ranitidine hydrochloride do not favor the traditional approach to sustained release delivery. Hence, clinically acceptable sustained release dosage forms of ranitidine hydrochloride prepared with conventional technology may not be successful.

It is also reported that oral treatment of gastric disorders with an $\mathrm{H}_{2}$ - receptor antagonist like ranitidine or famotidine, used in combination with antacids, promotes local delivery of these drugs to the receptor of the parietal cell wall. Local delivery of these drugs also increases the stomach wall receptor site bioavailability and increases the efficacy of drugs to reduce acid secretion. This principle may be applied for improving systemic as well as local delivery of ranitidine, which would efficiently reduce gastric acid secretion. ${ }^{[9]}$

Dave et al. developed a gastroretentive drug delivery system of ranitidine hydrochloride using HPMC K5M as the polymer and sodium bicarbonate as a gas-generating agent. The tablets were prepared by wet granulation method. ${ }^{[9]}$ A similar study was carried out by Kaza et al. The gastroretentive sustained release formulations of ranitidine hydrochloride were prepared by wet granulation method using polymers such as HPMC K100M and HPMC K15M. ${ }^{[10]}$ Khemariya et al. also developed gastroretentive tablets of ranitidine hydrochloride using Methocel K100 and Methocel K15M. The formulations were prepared by wet granulation method. ${ }^{[11]}$ Choudhary et al. formulated an extended release floating tablets of ranitidine hydrochloride using different concentrations of HPMC K4M, Carbopol 934 and sodium carboxymethyl cellulose. The tablets were prepared by wet granulation method. ${ }^{[12]}$

The literature review shows that most of the formulations of gastroretentive tablets of ranitidine hydrochloride have been developed using wet granulation method. In the present study, the formulation has been developed using dry granulation method. Hence, the formulation developed in the present study can be more economical as compared to the formulation developed in the previous studies.

Though HPMC has been used as a rate controlling polymer in controlled formulations, HPMC, when used alone, may exhibit an initial burst release for very soluble drugs. This behavior has been attributed to the rapid dissolution of the drug from the surface near the surface of the matrix, while the polymer undergoes hydration to form a protective gel layer. HPMC and PEO have been used for modulating drug release and to prevent the burst release of highly soluble drugs. ${ }^{[13]}$

The gastroretentive formulations are to be retained in the stomach for prolonged time. The residence time of drug formulation particles in the stomach can be prolonged by using particles that are small enough to be swallowed comfortably but swell to a larger size upon contact with the gastric fluid in the stomach. With a great enough degree of swelling, particles of this type achieve gastric retention regardless of whether the subject is in the fed mode or the fasted mode. PEO is a matrix material that possesses both swelling and controlled release properties. For the highly 
soluble drugs, the PEO component of the matrix limits the initial release of the drug and imparts gastric retention through swelling, while the HPMC component lowers the amount of PEO required while still allowing the swelling to occur. ${ }^{[14]}$

Hence, using PEO and HPMC in combination would be beneficial in achieving prolonged gastroretention along with sustained delivery of highly soluble drugs like ranitidine hydrochloride. In the present study, the gastroretentive tablets have been developed using PEO and HPMC. Dry granulation method has been employed to prepare the gastroretentive tablets. The study involves the use of novel polymer like PEO, having high degree of swelling and controlled release properties, for gastroretention while employing the simple method of dry granulation for preparing the gastroretentive tablets of ranitidine hydrochloride.

In the current work, floating tablets of ranitidine hydrochloride were prepared by effervescent approach using HPMC and PEO as the polymers. The aim of the study was to evaluate the effect of the polymers as well as the different grades of HPMC on drug release and the effect of sodium bicarbonate on buoyancy. The effect of effervescent agent (sodium bicarbonate) and release rate retardant (stearic acid) on drug release was also studied.

\section{MATERIALS AND METHODS}

\section{Materials}

Ranitidine hydrochloride was used as the active ingredient. HPMC (HPMC K15MCR and HPMC K100MCR) and PEO (Polyox WSR303) were used as the polymers. Sodium bicarbonate was used an effervescent agent. The other ingredients used were stearic acid, magnesium stearate, talc, aerosol 200 and avicel PH101. All the materials used in experimental works were obtained from Ranbaxy Research Laboratories, Gurgaon, India. All reagents used were of analytical grade.

\section{Methods}

Preparation of floating tablets of ranitidine bydrocbloride

The composition of different formulation of ranitidine hydrochloride floating tablets is shown in Table 1. Ranitidine hydrochloride (336 mg equivalent to $300 \mathrm{mg}$ of ranitidine) and all other ingredients were weighed separately and passed through sieve no. 25. The active ingredient, HPMC, Avicel (Microcrystalline cellulose) and $50 \%$ of the lubricants were mixed together. The mixture was then compacted in a slugging machine to form the compacts. The compacts were then milled and passed through sieve no. 18 followed by sieve no. 60. The particles that retained on sieve no. 60 were taken as granules and those passing through the sieve were fines. The fines were again compacted, milled and sieved through sieve no. 18 and 60 . The cycle of compaction- milling- sieving was repeated until the granules and fines were obtained in the ratio of about 70:30. The granules and fines were then mixed together and the remaining ingredients except magnesium stearate were added to it and mixed. The remaining lubricant i.e. magnesium stearate was then added and mixed to the above mixture to form the final blend. The final blend was compressed into tablets using single punch tablet rotary press (Cadmach).

\section{In-vitro buoyancy studies}

The in vitro buoyancy was determined by floating lag time and total floating time as per the method described by Roy et al. ${ }^{[15]}$ The tablets $(n=3)$ were placed in 1000 $\mathrm{ml}$ of $0.01 \mathrm{~N} \mathrm{HCl}$ in USP type II dissolution apparatus $\left(37 \pm 0.5^{\circ} \mathrm{C}, 50 \mathrm{rpm}\right)$. The time required for the tablets to rise to the surface and float was determined as floating lag time. The duration of time the dosage form constantly remained on the surface was determined as the total floating time.

\section{In-vitro dissolution studies}

The release of ranitidine from floating tablets $(n=3)$ was determined using USP XXXII dissolution testing apparatus type II (paddle method). The dissolution was performed using $1000 \mathrm{ml}$ of $0.01 \mathrm{~N} \mathrm{HCl}$, at $37 \pm 0.5^{\circ} \mathrm{C}$ and $50 \mathrm{rpm}$. A sample $(5 \mathrm{ml})$ of the solution was withdrawn from the dissolution apparatus at predetermined time intervals $(0.5$, 1, 2, 3, 6, 9, 12, 15, 18 and 24 hours) and the samples were replaced with fresh dissolution medium. The samples were filtered through $0.45 \mu$ membrane (nylon) filter and diluted to suitable concentration with $0.01 \mathrm{~N} \mathrm{HCl}$. The samples were analyzed for drug release against $0.01 \mathrm{~N} \mathrm{HCl}$ as a blank at a wavelength of $314 \eta \mathrm{m}$ using a Shimadzu UV- 1700 $\mathrm{UV} /$ Vis double beam spectrophotometer. The percentage drug release was calculated by the following formula:

The times for $50 \%$ and $80 \%$ drug release i.e. $\mathrm{t}_{50 \%}$ and $\mathrm{t}_{80 \%}$ were calculated based on the Higuchi model.

\section{Kinetic modelling of drug release}

To analyze the mechanism of drug release from the floating tablets, the in vitro dissolution data of the formulations were 
Gharti, et al:: Floating tablets of ranitidine hydrochloride

Table 1: Formulation composition of ranitidine hydrochloride floating tablets

\begin{tabular}{|c|c|c|c|c|c|c|c|c|c|c|c|}
\hline S.N. & Batch No & R HCl & K15M & K100M & PEO & SB & SA & Talc & MS & Avicel & Total \\
\hline 1 & KPG(120)42 & $336(61.09)$ & $40(7.27)$ & - & $40(7.27)$ & $20(3.63)$ & - & $6(1.09)$ & $3(0.54)$ & 105 (19.09) & $550(100)$ \\
\hline 2 & KPG(120)45 & $336(61.09)$ & $40(7.27)$ & - & $60(10.91)$ & $20(3.63)$ & - & $6(1.09)$ & $3(0.54)$ & $85(15.45)$ & $550(100)$ \\
\hline 3 & KPG(120)48 & $336(61.09)$ & $60(10.91)$ & - & $40(7.27)$ & $20(3.63)$ & - & $6(1.09)$ & $3(0.54)$ & $85(15.45)$ & $550(100)$ \\
\hline 4 & KPG(121)01 & $336(61.09)$ & $60(10.91)$ & - & $60(10.91)$ & $20(3.63)$ & - & $6(1.09)$ & $3(0.54)$ & $65(11.81)$ & $550(100)$ \\
\hline 5 & KPG(121)04 & $336(61.09)$ & - & $40(7.27)$ & $60(10.91$ & $20(3.63)$ & - & $6(1.09)$ & $3(0.54)$ & $85(15.45)$ & $550(100)$ \\
\hline 6 & KPG(121)07 & $336(51.7)$ & - & $60(9.23)$ & $60(9.23)$ & $20(3.07)$ & - & $6(0.92)$ & $3(0.46)$ & $165(25.38)$ & $650(100)$ \\
\hline 7 & KPG(121)10 & $336(51.7)$ & - & $80(7.27)$ & $60(9.23)$ & $20(3.07)$ & - & $6(0.92)$ & $3(0.46)$ & $145(22.30)$ & $650(100)$ \\
\hline 8 & KPG(121)14 & $336(049.05)$ & - & $60(8.76)$ & $60(8.76)$ & $20(2.92)$ & $35(5.11)$ & $6(0.87)$ & $3(0.43)$ & $165(24.08)$ & $685(100)$ \\
\hline 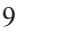 & KPG(121)17 & $336(53.33)$ & $60(9.52)$ & - & $60(9.52)$ & $30(4.76)$ & $50(7.93)$ & $6(0.95)$ & $3(0.47)$ & 85 (13.07) & $630(100)$ \\
\hline 10 & KPG(121)20 & $336(54.63)$ & $60(9.75)$ & - & $60(9.75)$ & $30(4.87)$ & $35(9.75)$ & $6(0.97)$ & $3(0.48)$ & $85(13.82)$ & $615(100)$ \\
\hline 11 & KPG(121)23 & $336(56.00)$ & $60(10.00)$ & - & $60(10.00)$ & $30(5.00)$ & $20(3.33)$ & $6(1.00)$ & $3(0.50)$ & $85(14.16)$ & $600(100)$ \\
\hline 12 & KPG(121)26 & $336(56.95)$ & $60(10.17)$ & - & $60(10.17)$ & $20(3.89)$ & $20(3.89)$ & $6(1.01)$ & $3(0.50)$ & $85(14.40)$ & $590(100)$ \\
\hline 13 & KPG(121)29 & $336(55.53)$ & $60(9.91)$ & - & $60(9.91)$ & $20(3.30)$ & $35(5.78)$ & $6(1.00)$ & $3(0.50)$ & $85(14.05)$ & $605(100)$ \\
\hline 14 & KPG(121)32 & $336(54.20)$ & $60(9.67)$ & - & $60(9.67)$ & $20(3.22)$ & $50(8.06)$ & $6(0.97)$ & $3(0.48)$ & 85 (13.71) & $620(100)$ \\
\hline 15 & KPG(121)35 & $336(57.93)$ & $60(10.34)$ & - & $60(10.34)$ & $10(1.72)$ & $20(3.44)$ & $6(1.03)$ & $3(0.52)$ & $85(14.65)$ & $580(100)$ \\
\hline 16 & KPG(121)38 & $336(55.08)$ & $60(9.83)$ & - & $60(9.83)$ & $10(1.64)$ & $50(8.19)$ & $6(0.98)$ & $3(0.49)$ & $85(13.93)$ & $610(100)$ \\
\hline 17 & KPG(121)41 & $336(56.47)$ & $60(10.08)$ & - & $60(9.83)$ & $10(1.68)$ & $35(5.88)$ & $6(1.01)$ & $3(0.50)$ & $85(14.28)$ & $595(100)$ \\
\hline 18 & KPG(121)44 & $336(49.41)$ & $60(8.82)$ & - & $100(14.7)$ & $20(2.94)$ & - & $6(0.88)$ & $3(0.44)$ & $155(22.8)$ & $680(100)$ \\
\hline 19 & KPG(121)47A & $336(46.66)$ & $100(13.88)$ & - & $100(13.88)$ & $20(2.77)$ & - & $6(0.83)$ & $3(0.41)$ & $155(21.52)$ & $720(100)$ \\
\hline 20 & KPG(121)47B & $336(49.41)$ & $100(14.7)$ & - & $60(8.82)$ & $20(2.94)$ & - & $6(0.88)$ & $3(0.44)$ & $155(22.8)$ & $680(100)$ \\
\hline
\end{tabular}

$\mathrm{RHCl}=$ Ranitidine hydrochloride $\mathrm{K} 15 \mathrm{M}=\mathrm{HPMC} \mathrm{K} 15 \mathrm{MCR}, \mathrm{K} 100 \mathrm{M}=$ HPMC K100MCR, PEO = PolyoxWSR303, SB = Sodium bicarbonate, SA = Stearic Acid,

MS = Magnesium Stearate, ${ }^{*}$ All quantities are in $\mathrm{mg}$. The weights given are for each tablet, ${ }^{*}$ The figures within the brackets indicate the percentage composition of each ingredient

fitted to the zero order, first order, Higuchi model and Korsmeyer- Peppas model as per the method described by Dash et al. ${ }^{[16]}$

\section{RESULTS AND DISCUSSION}

\section{In vitro buoyancy studies}

The tablets were prepared by effervescent technique using sodium bicarbonate as a gas generating agent. Sodium bicarbonate induced carbon dioxide generation in the presence of dissolution medium $(0.01 \mathrm{~N} \mathrm{HCl})$. The gas generated is trapped and protected within the gel, formed by hydration of polymer, thus decreasing the density of the tablet. As the density of the tablet falls below $1 \mathrm{~g} / \mathrm{ml}$, the tablet becomes buoyant. ${ }^{[17]}$ The effect of sodium bicarbonate on buoyancy of the tablets was evaluated by using it at three different levels- 30, 20 and $10 \mathrm{mg}$ per tablet. The results of in vitro buoyancy are shown in Table 2 . All the formulations maintained their matrix integrity for more than 24 hours. The result shows that the total floating time for the formulations was more than 24 hours irrespective to the amount of sodium bicarbonate whereas floating lag time decreases with increasing amount of sodium bicarbonate. The amount of carbon dioxide produced is exclusively proportional to the quantity of sodium bicarbonate in the tablet. ${ }^{[18]}$ Decrease in floating lag time of the formulations can be attributed to the availability of an increased amount of carbon dioxide as the concentration of sodium bicarbonate was increased, being entrapped in the formed gel to give rapid buoyancy. Sodium bicarbonate at the level of $20 \mathrm{mg}$ per tablet showed a floating lag time of 83 to 106 seconds. This value is close to the result in the study by Kaza et al. ${ }^{[1]}$ Hence, sodium bicarbonate (20 mg per tablet) was essential to achieve optimum in vitro buoyancy.

In vitro dissolution studies

The result of in-vitro dissolution study has been listed in Table 3 and $t_{50 \%}$ and $t_{80 \%}$ of the formulated batches has been shown in Table 4.

Effect of polymer concentrations over drug release

To evaluate the effect of the polymer concentration over drug release, HPMC K15MCR and Polyox WSR303 were used in combination at 3 different levels- 40, 60 and $100 \mathrm{mg}$ per tablet. The drug release profile as been shown in Figure 1. The formulation containing the polymers at concentration of $13.88 \%$ showed $91.2 \%$ drug release at the end of 24 hours. The result shows that the drug release can be reduced by increasing the concentration of polymers. The results of this study are consistent with findings in a previous report by Enayatifard et al., which showed that the presence of a highly water- soluble compound in a HPMC matrix generates an additional osmotic gradient, thereby resulting in a faster rate of polymer swelling and large increase in gel thickness. ${ }^{[19]}$ At higher polymer loading, the viscosity of the gel matrix is 
increased which results in a decrease in the effective diffusion coefficient of the drug and hence decreased drug release into

Table 2: Buoyancy of formulated ranitidine hydrochloride floating tablets

\begin{tabular}{lcccc}
\hline S.N. & Batch No & Floating lag time & $\begin{array}{c}\text { Matrix } \\
\text { integrity }\end{array}$ & $\begin{array}{c}\text { Total } \\
\text { floating } \\
\text { time }\end{array}$ \\
\hline 1 & KPG(120)42 & $55-68 \mathrm{sec}$ & + & $>24$ hours \\
2 & KPG(120)45 & $63-68 \mathrm{sec}$ & + & $>24$ hours \\
3 & KPG(120)48 & $84-88 \mathrm{sec}$ & + & $>24$ hours \\
4 & KPG(121)01 & $77-90 \mathrm{sec}$ & + & $>24$ hours \\
5 & KPG(121)04 & $22-33 \mathrm{sec}$ & + & $>24$ hours \\
6 & KPG(121)07 & $102-115 \mathrm{sec}$ & + & $>24$ hours \\
7 & KPG(121)10 & $65-85 \mathrm{sec}$ & + & $>24$ hours \\
8 & KPG(121)14 & $60-70 \mathrm{sec}$ & + & $>24$ hours \\
9 & KPG(121)17 & $20-25 \mathrm{sec}$ & + & $>24$ hours \\
10 & KPG(121)20 & $20-40 \mathrm{sec}$ & + & $>24$ hours \\
11 & KPG(121)23 & $18-30 \mathrm{sec}$ & + & $>24$ hours \\
12 & KPG(121)26 & $60-105 \mathrm{sec}$ & + & $>24$ hours \\
13 & KPG(121)29 & $84-116 \mathrm{sec}$ & + & $>24$ hours \\
14 & KPG(121)32 & $101-110 \mathrm{sec}$ & + & $>24$ hours \\
15 & KPG(121)35 & 4 min $20 \mathrm{sec}-10 \mathrm{~min} 45 \mathrm{sec}$ & + & $>24$ hours \\
16 & KPG(121)38 & 2 min $40 \mathrm{sec}-11 \mathrm{~min} 15 \mathrm{sec}$ & + & $>24$ hours \\
17 & KPG(121)41 & 8 min $42 \mathrm{sec}-19 \mathrm{~min} 15 \mathrm{sec}$ & + & $>24$ hours \\
18 & KPG(121)44 & $80-180 \mathrm{sec}$ & + & $>24$ hours \\
19 & KPG(121)47A & $130-140 \mathrm{sec}$ & + & $>24$ hours \\
20 & KPG(121)47B & $75-85 \mathrm{sec}$ & + & $>24$ hours \\
\hline
\end{tabular}

the dissolution medium. ${ }^{[20]}$

The effect of polymer concentration on $\mathrm{t}_{50 \%}$ and $\mathrm{t}_{80 \%}$ of the formulations was also evaluated. Previous studies also show that $\mathrm{t}_{50 \%}$ and $\mathrm{t}_{80 \%}$ have been compared to evaluate the effect on drug release by varying the concentration of polymers. The results of the present study are consistent with the findings in previous report by Kumar et al. and Prajapati et al. The authors have also reported that $\mathrm{t}_{50 \%}$ and $t_{80 \%}$ was delayed in the formulations containing higher concentration of polymers. ${ }^{[21,22]}$ The presence of hydrophilic polymers like HPMC and Polyox in a matrix tablet would result in dynamic formation and change of a hydrogel layer on the surface of the tablet upon contact with water. Solid drug- polymer matrix core will transform from its initial dry (glassy) stage to a wet (rubbery) stage while dissolution medium is permeating through tablet surface. Drug release rate and extent are inversely proportional to the thickness of this hydrogel layer, because it takes time for drug molecules to travel across the gel layer and reach the dissolution medium. The higher proportion of polymer in the tablet enables the formation of a thicker hydrogel layer and subsequently delays the time required for drug release. ${ }^{[23]}$

Table 3: Dissolution profiles of floating tablets $(n=3)$ of ranitidine hydrochloride

\begin{tabular}{|c|c|c|c|c|c|c|c|c|c|c|c|}
\hline \multirow[t]{2}{*}{ S.N. } & \multirow[t]{2}{*}{ Batch no. } & \multicolumn{10}{|c|}{ Cumulative $\%$ drug release \pm SD } \\
\hline & & $0.5 \mathrm{~h}$ & $1 \mathrm{~h}$ & $2 \mathrm{~h}$ & $3 \mathrm{~h}$ & $6 \mathrm{~h}$ & $9 \mathrm{~h}$ & $12 \mathrm{~h}$ & $15 \mathrm{~h}$ & $18 \mathrm{~h}$ & $24 \mathrm{~h}$ \\
\hline 1 & KPG(120)42 & $0.9 \pm 1.2$ & $.9 \pm 2.1$ & $4 \pm 2.3$ & $.0 \pm 2.9$ & 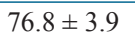 & s & $3 \pm 1.7$ & $5.6 \pm 0.7$ & 5 & \pm 1.1 \\
\hline & $\mathrm{PG}(120) 45$ & $9 \pm 0.5$ & .3 & .1 & .7 & 1.5 & $0 \pm 2.9$ & .5 & $.7 \pm 0.8$ & 1.4 & .2 \\
\hline & KPG(120)48 & $17.3 \pm 1.1$ & $7.6 \pm 1.6$ & $4.2 \pm 2.5$ & $56.9 \pm 3.0$ & $71.8 \pm 4.7$ & $82.7 \pm 2.9$ & $4=-10$ & $.2 \pm 1.6$ & $3.7 \pm 0.8$ & 1.8 \\
\hline 4 & KPG & 1 & 6 & .2 & 5 & 4 & 9 & & 2.0 & & 2.0 \\
\hline 5 & KPG(121)04 & $14.3 \pm$ & $3.2 \pm 0.7$ & $41.9 \pm$ & $51.6 \pm$ & $70.3=$ & $81.3=$ & $88.8 \pm$ & $93.4 \pm 1.0$ & 1.7 & $99.9 \pm 0.8$ \\
\hline & KPG(121)07 & $17.7 \pm 2.6$ & $26.2 \pm 1.6$ & $38.7 \pm 1.2$ & $47.8 \pm 1.2$ & $65.1 \pm 2.1$ & $77.6 \pm 4.0$ & $85.0 \pm 2.3$ & $91.8 \pm 4.4$ & $95.3 \pm 2.1$ & $97.5 \pm 2.7$ \\
\hline 7 & K & 17.1 & $264+$ & $39.1 \pm$ & $48.3 \pm 1.3$ & $67.3 \pm 2.5$ & $75.8 \pm 1.1$ & $84.7 \pm$ & $91.5 \pm 2.3$ & .3 & $7 \pm 1.3$ \\
\hline 0 & KPG(121)14 & $13.4 \pm 1.3$ & $21.7 \pm 1.3$ & $31.5 \pm 0.9$ & $40.5 \pm 1.1$ & $62.2 \pm 0.4$ & $75.4 \pm 1.5$ & $82.3 \pm 0.8$ & $86.5 \pm 1.1$ & $90.8 \pm 2.2$ & $98.7 \pm 1.1$ \\
\hline T & 17 & 4 & $.5 \pm$ & .7 & $44.8 \pm 3.3$ & $68.1 \pm 1.2$ & $80.1 \pm$ & $88.8 \pm 2.2$ & $95.3 \pm 2.4$ & 2.7 & 2.0 \\
\hline 10 & 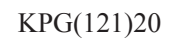 & $10.1+0$. & $20.0-2.0$ & $36.0 \pm 1.7$ & $46.2 \pm 1.8$ & $66.4 \pm 3.2$ & $80.2 \pm 1.8$ & 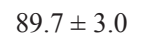 & $95.0 \pm 2.3$ & $98.7 \pm 3.3$ & $101.9 \pm 1.9$ \\
\hline 11 & KPG(121)23 & $17.3 \pm 0.7$ & $24.1 \pm 1.8$ & $38.2 \pm 3.4$ & $47.4 \pm 2.8$ & $64.0 \pm 3.4$ & $82.0 \pm 5.1$ & $90.4 \pm 5.5$ & $93.8 \pm 4.8$ & $98.9 \pm 1.5$ & $101.6 \pm 2.6$ \\
\hline 12 & KPG(121)26 & $16.4 \pm 2.4$ & $25.6 \pm 1.8$ & $37.5 \pm 1.8$ & $46.9 \pm 1.8$ & $67.4 \pm 1.5$ & $80.1 \pm 0.5$ & $90.3 \pm 1.9$ & $92.5 \pm 2.0$ & $98.7 \pm 0.3$ & $100.6 \pm 1.3$ \\
\hline 13 & KPU & $17.8 \pm 0.9$ & 2 & $2+0$ & $49.2 \pm 0.2$ & $69.4 \pm 1.8$ & $84.8 \pm 0.5$ & $92.4 \pm 1.1$ & $96.0 \pm 0.5$ & $97.6 \pm 0.6$ & $98.9 \pm 1.0$ \\
\hline 14 & KPG & 16 & $24.5 \pm 1.1$ & 3 & $45.8 \pm$ & $66.1 \pm$ & $79.8 \pm 2.4$ & 89 & 94 & .2 & 99. \\
\hline 15 & KPG(121)35 & $20.5 \pm 0.7$ & $27.9 \pm 1.2$ & $40.9 \pm 0.7$ & $51.8 \pm 1.0$ & $72.2 \pm 0.5$ & $85.8 \pm 1.5$ & $93.4 \pm 2.8$ & $96.3 \pm 1.1$ & $98.9 \pm 1.0$ & $99.8 \pm 1.2$ \\
\hline 16 & KPG(121)38 & $19.4 \pm 1.2$ & $27.5 \pm 1.3$ & $40.8 \pm 1.4$ & $51.7 \pm 1.6$ & $73.2 \pm 3.2$ & $84.5 \pm 0.7$ & $91.7 \pm 1.4$ & $96.6 \pm 1.3$ & $98.2 \pm 1.5$ & $100.3 \pm 0.6$ \\
\hline 17 & KPG(121)41 & 02 & $7+17$ & $42.3 \pm 1.8$ & $52.9 \pm 2.5$ & $73.6 \pm 1$. & $85.2 \pm 2.1$ & $91.0 \pm 1$ & $97.3 \pm 0$ & $99.0 \pm 0.0$ & $99.9 \pm$ \\
\hline 18 & KPG( & $15.6=$ & $22.4 \pm$ & $34.1 \pm 1.0$ & $42.4 \pm$ & 61.3 & $74.8 \pm$ & 86.2 & $91.8 \pm$ & $92.6 \pm 0.6$ & $93.6 \pm 0.5$ \\
\hline 19 & KPG(121)47A & $14.8 \pm 0.6$ & $23.2 \pm 1.6$ & $35.5 \pm 2.6$ & $43.6 \pm 2.6$ & $60.7 \pm 3.2$ & $72.9 \pm 1.5$ & $81.6 \pm 2.4$ & $86.3 \pm 4.3$ & $89.0 \pm 1.5$ & $91.2 \pm 0.9$ \\
\hline 20 & KPG(121)47B & $13.3 \pm 0.2$ & $22.2 \pm 0.8$ & $34.6 \pm 0.4$ & $43.9 \pm 0.2$ & $63.5 \pm 1.1$ & $76.4 \pm 1.1$ & $89.8 \pm 0.6$ & $92.2 \pm 0.7$ & $94.7 \pm 0.4$ & $95.0 \pm 0.3$ \\
\hline
\end{tabular}


Effect of different viscosity grades of HPMC over drug release

The effect of HPMC grades over drug release was evaluated by using 2 different viscosity grades of HPMC- K15MCR and K100MCR. These polymers were used at 2 different levels (40 and $60 \mathrm{mg}$ per tablet) i.e. $7.27 \%$ and $10 \%$ with fixed level (60 mg per tablet) of Polyox WSR303. The drug release profile has been shown in Figure 2. The drug release curve clearly shows that there is no significant difference in drug release upon changing the viscosity grade of HPMC from K15MCR to K100MCR. The effect of different viscosity grades of HPMC on $t_{50 \%}$ and $t_{80 \%}$ was also evaluated. The significant difference on $\mathrm{t}_{50 \%}$ and $\mathrm{t}_{80 \%}$ by changing the viscosity grade of HPMC was studied by one- way ANOVA (analysis of variance) at 0.05 level of significance. The result showed that there was no significant difference in $t_{50 \%}$ and $\mathrm{t}_{80 \%}$ upon changing the viscosity grade of HPMC. Algin et al. also found that formulations containing Methocel $\mathrm{K} 15 \mathrm{M}$ and $\mathrm{K} 100 \mathrm{M}$ showed similar release profiles for verapamil hydrochloride. ${ }^{[24]}$ Rao $e t$ al. have reported that at higher concentration of HPMC, the viscosity did not significantly affect the drug release. ${ }^{[25]}$ The result of present study is also supported by those of a previous study by Thapa et al. in which no significant difference in nicotine release was found between the formulations containing HPMC K15MP and K100MP. ${ }^{[26]}$ A threshold effect may be attained at a specific viscosity grade of HPMC for a drug. Increasing HPMC viscosity above that grade may not further retard the drug release rate. In the present study, K15MCR and K100MCR formulations had identical drug release profiles which suggested the existence of a 'limiting HPMC viscosity', around 15,000 cps, for the systems studied at which drug release rate no longer decreased with viscosity. There is no apparent benefit of using high viscosity HPMC (K100MCR versus K15MCR) for designing sustained release formulations for highly soluble drug like ranitidine hydrochloride.

Effect of sodium bicarbonate and stearic acid over drug release

The effect of sodium bicarbonate and stearic acid over drug release was evaluated by using sodium bicarbonate at 3 different levels (30, 20 and $10 \mathrm{mg}$ per tablet) and stearic acid at 3 different levels (50, 35 and $20 \mathrm{mg}$ per tablet). The drug release profile has been shown in Figure 3. The result shows that there is no significant difference in drug release profile upon changing the concentration of sodium bicarbonate and stearic acid. The result is supported by the study carried out by Fukuda et al. and Rao et al. which showed that sodium bicarbonate did not have significant

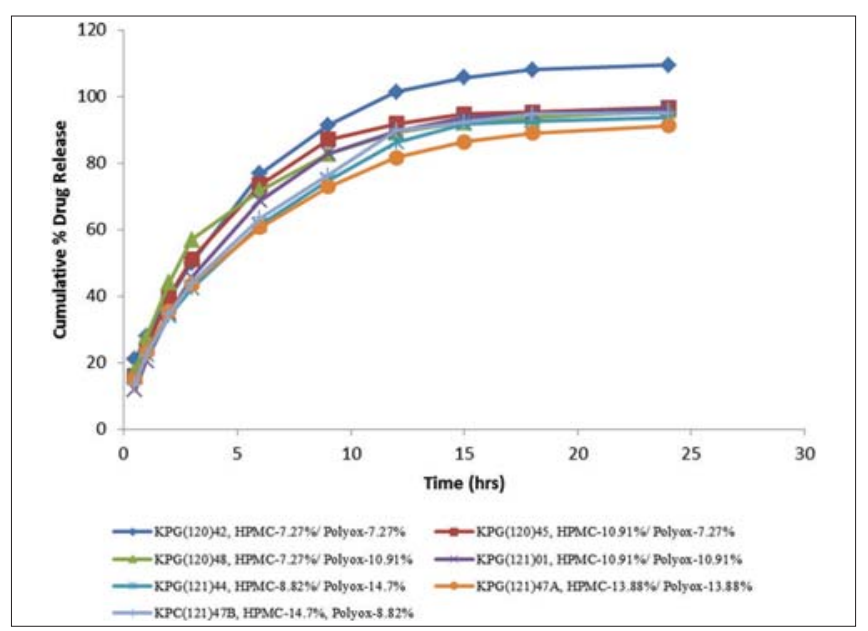

Figure 1: Effect of polymer concentration over drug release

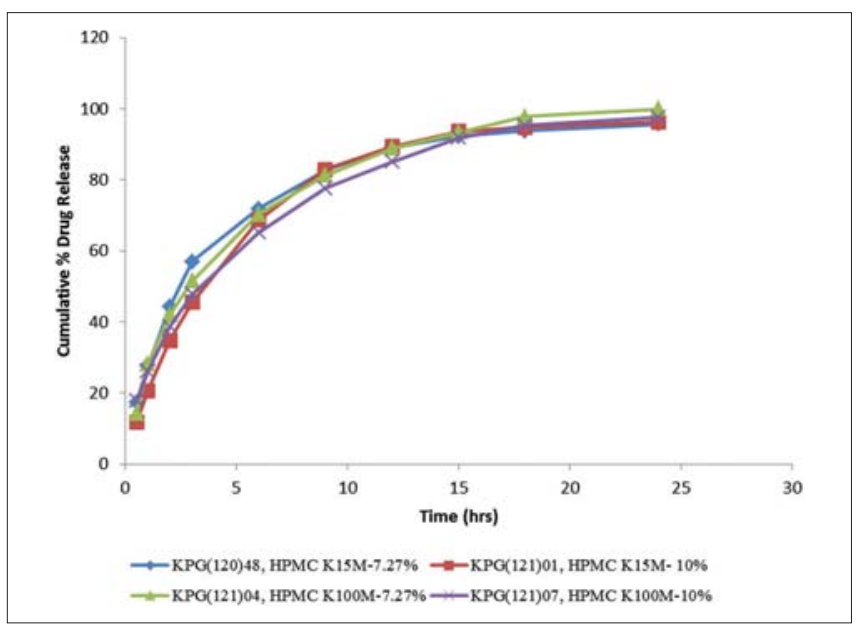

Figure 2: Effect of different viscosity grades of HPMC over drug release

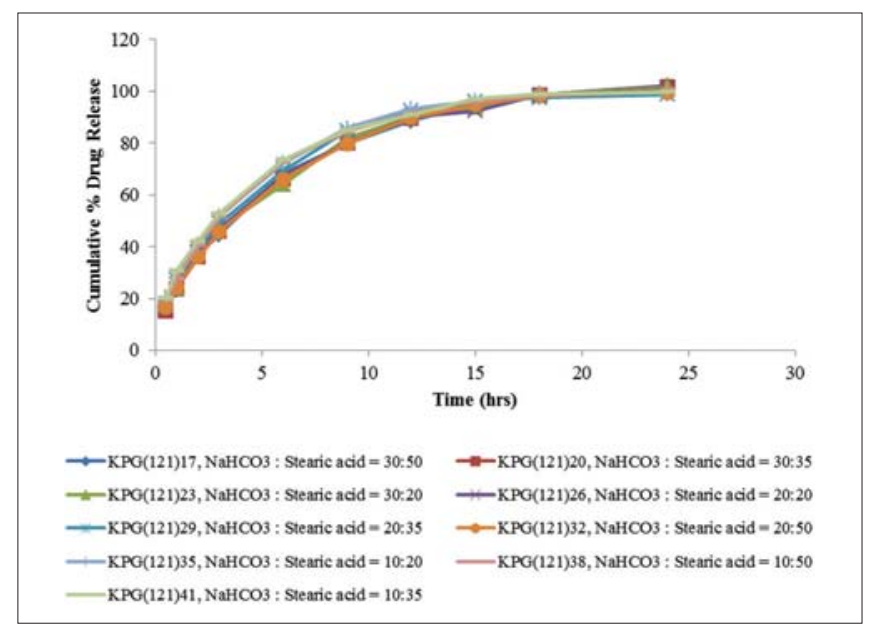

Figure 3: Effect of sodium bicarbonate and stearic acid over drug release

effect on drug release profile. ${ }^{[25,27]}$ Sodium bicarbonate, upon contact with the dissolution medium, results in the development of carbon dioxide gas. ${ }^{[28]}$ These carbon 
dioxide bubbles enlarge the matrix volume, allowing an increase in the drug release rate. However, at the same time, the carbon dioxide bubbles get dispersed in the matrix and may cause partial obstruction of the diffusion path. The presence of the gas bubbles slows down the water transport in the direction of the matrix as well as the transport of the dissolved drug towards the outside of the matrix. ${ }^{[2]}$ Moreover, stearic acid, being hydrophobic in nature, inhibits the penetration of water into the matrix and may reduce the drug dissolution. ${ }^{[30]}$ Hence, sodium bicarbonate and stearic acid in combination may not have any overall effect on drug release.

\section{Kinetic modelling of drug release}

The dissolution data of all the formulations were fitted to zero order, first order, Higuchi model and KorsmeyerPeppas model to study the drug release kinetics. In practice, there is often seen that the linear relationship between the amount of drug liberated and the square root of time is only true in a part of the dissolution curve $(75$ to $80 \%$ of the time needed for complete liberation of the drug) or 75 to $80 \%$ of the drug released. ${ }^{[31,32]}$ Hence, the dissolution data were fitted by plotting the cumulative percentage drug release against the square root of time up to 12 hours. Higuchi model gave a good fit to all dissolution profiles for all formulations as shown by regression coefficient $\mathrm{R}^{2}$ value $\left(0.96<\mathrm{R}^{2}<1\right)$. The result of drug release kinetics is shown in Table 5. Changing the concentrations of polymers or changing the viscosity grades of HPMC had

\begin{tabular}{lccc}
$\begin{array}{l}\text { Table 4: } \mathbf{t}_{50 \%} \text { and } \mathbf{t}_{80 \%} \text { of formulated batches of } \\
\text { ranitidine hydrochloride }\end{array}$ \\
\hline S. N. & Batch no. & $\mathbf{t}_{50 \%}(\mathbf{h r})$ & $\mathbf{t}_{80 \%}(\mathbf{h r})$ \\
\hline 1 & $\mathrm{KPG}(120) 42$ & 3.48 & 11.59 \\
2 & $\mathrm{KPG}(120) 45$ & 4.05 & 12.85 \\
3 & $\mathrm{KPG}(120) 48$ & 3.62 & 13.14 \\
4 & $\mathrm{KPG}(121) 01$ & 5.23 & 13.51 \\
5 & $\mathrm{KPG}(121) 04$ & 4.21 & 12.88 \\
6 & $\mathrm{KPG}(121) 07$ & 5.44 & 15.28 \\
7 & $\mathrm{KPG}(121) 10$ & 4.84 & 13.74 \\
8 & $\mathrm{KPG}(121) 14$ & 6.19 & 14.51 \\
9 & $\mathrm{KPG}(121) 17$ & 4.88 & 12.93 \\
10 & $\mathrm{KPG}(121) 20$ & 4.96 & 12.98 \\
11 & $\mathrm{KPG}(121) 23$ & 4.75 & 12.93 \\
12 & $\mathrm{KPG}(121) 26$ & 4.73 & 13.04 \\
13 & $\mathrm{KPG}(121) 29$ & 4.12 & 12.69 \\
14 & $\mathrm{KPG}(121) 32$ & 4.89 & 13.1 \\
15 & $\mathrm{KPG}(121) 35$ & 3.6 & 12.32 \\
16 & $\mathrm{KPG}(121) 38$ & 3.63 & 12.41 \\
17 & $\mathrm{KPG}(121) 41$ & 3.35 & 12.25 \\
18 & $\mathrm{KPG}(121) 44$ & 5.76 & 14.36 \\
19 & $\mathrm{KPG}(121) 47 \mathrm{~A}$ & 6.03 & 15.21 \\
20 & $\mathrm{KPG}(121) 47 \mathrm{~B}$ & 5.54 & 13.92 \\
\hline
\end{tabular}

no significant difference in $\mathrm{R}^{2}$ values. Among the different models studied, the dissolution data best fitted to Higuchi model as indicated by the $\mathrm{R}^{2}$ values. Hence, the drug release was proportional to the square root of time. To study the mechanism of drug release, the drug release data were fitted to Korsmeyer- Peppas equation. Diffusion exponent " $\mathrm{n}$ " values were obtained in the range of 0.4383 to 0.5517 . The result shows that the drug release from the formulated tablets was by non- Fickian diffusion. However, despite Fickian diffusion in the matrix, boundary conditions such as the presence of a stagnant layer or a net charge faced on the release surface may have given origin to a release kinetics characterized by $n$ greater than 0.5 .

\section{CONCLUSION}

The floating tablets of ranitidine hydrochloride were prepared by dry granulation method based on effervescent approach. HPMC and Polyox were used as the polymers and sodium bicarbonate was used as a gas generating approach. It was seen that increasing the concentration of polymers (HPMC K15MCR and Polyox WSR303) delayed the drug release profile. However, there was no effect on drug release profile upon changing the viscosity grades of HPMC (K15MCR to K100MCR). Increasing the amount of sodium bicarbonate decreased the floating lag time. But the amount of sodium bicarbonate did not have any effect on total floating time of formulations. Changing the concentrations

\section{Table 5: Regression coefficient $\left(R^{2}\right)$ values of} formulated batches

\begin{tabular}{|c|c|c|c|c|c|c|}
\hline \multirow[t]{2}{*}{ S.N. } & \multirow[t]{2}{*}{ Batch no. } & \multirow{2}{*}{$\begin{array}{c}\begin{array}{c}\text { Zero } \\
\text { order }\end{array} \\
R^{2} \\
\end{array}$} & \multirow{2}{*}{$\begin{array}{c}\begin{array}{c}\text { First } \\
\text { order }\end{array} \\
R^{2} \\
\end{array}$} & \multirow{2}{*}{$\begin{array}{c}\text { Higuchi } \\
R^{2}\end{array}$} & \multicolumn{2}{|c|}{ Korsmeyer- Peppas } \\
\hline & & & & & $R^{2}$ & $n$ \\
\hline 1 & KPG(120)42 & 0.8198 & 0.9884 & 0.9949 & 0.9800 & 0.4658 \\
\hline 2 & KPG(120)45 & 0.7575 & 0.9436 & 0.9835 & 0.9542 & 0.4819 \\
\hline 3 & KPG(120)48 & 0.7622 & 0.9603 & 0.9677 & 0.9455 & 0.4383 \\
\hline 4 & KPG(121)01 & 0.7884 & 0.9622 & 0.9901 & 0.9575 & 0.5517 \\
\hline 5 & KPG(121)04 & 0.8124 & 0.9254 & 0.9792 & 0.9506 & 0.4791 \\
\hline 6 & KPG(121)07 & 0.8463 & 0.9958 & 0.9927 & 0.9829 & 0.4515 \\
\hline 7 & KPG(121)10 & 0.8424 & 0.9978 & 0.987 & 0.9785 & 0.4531 \\
\hline 8 & KPG(121)14 & 0.8669 & 0.9540 & 0.9944 & 0.9838 & 0.5216 \\
\hline 9 & KPG(121)17 & 0.8495 & 0.9594 & 0.9942 & 0.9835 & 0.4909 \\
\hline 10 & KPG(121)20 & 0.8468 & 0.9699 & 0.9967 & 0.9805 & 0.5053 \\
\hline 11 & KPG(121)23 & 0.8475 & 0.9531 & 0.9963 & 0.9829 & 0.4788 \\
\hline 12 & KPG(121)26 & 0.8045 & 0.9499 & 0.9969 & 0.9805 & 0.4794 \\
\hline 13 & KPG(121)29 & 0.8044 & 0.9932 & 0.9954 & 0.9743 & 0.4595 \\
\hline 14 & KPG(121)32 & 0.8408 & 0.9793 & 0.9982 & 0.9833 & 0.4845 \\
\hline 15 & KPG(121)35 & 0.7997 & 0.9886 & 0.9932 & 0.9752 & 0.4351 \\
\hline 16 & KPG(121)38 & 0.8033 & 0.9958 & 0.9885 & 0.9737 & 0.4439 \\
\hline 17 & KPG(121)41 & 0.8021 & 0.9722 & 0.9863 & 0.9738 & 0.4231 \\
\hline 18 & KPG(121)44 & 0.8364 & 0.9475 & 0.9996 & 0.9829 & 0.4915 \\
\hline 19 & $\mathrm{KPG}(121) 47 \mathrm{~A}$ & 0.8371 & 0.9654 & 0.9954 & 0.9780 & 0.4782 \\
\hline 20 & KPG(121)47B & 0.8209 & 0.9470 & 0.9987 & 0.9728 & 0.5214 \\
\hline
\end{tabular}


of sodium bicarbonate and stearic acid had no significant effect on drug release profile. Hence from the present study, it can be concluded that hypromellose (HPMC K15MCR) and PEO (Polyyox WSR303) in appropriate concentration can be used to develop sustained release floating tablets of ranitidine hydrochloride by incorporating appropriate concentration of sodium bicarbonate for gas generation. Such system can remain buoyant for 24 hours along with the sustained drug release for the same duration.

\section{REFERENCES}

1. Dehghan MH, Khan FN. Gastroretentive drug delivery systems: A patent perspective. Int J Health Res 2009;2:23-44.

2. Rocca JG, Omidian H, Shah K. Progress in gastroretentive drug delivery systems. Business briefing. Pharma Tech 2003;5:152-6.

3. Mathur P, Saroha K, Syan N, Verma S, Kumar V. Floating drug delivery systems: An innovative acceptable approach in gastroretentive drug delivery. Arch Apll Sci Res 2010;2:257-70.

4. Shah SH, Patel JK, Patel NV. Stomach specific floating drug delivery system: A review. Int J Pharm Tech Res 2009;1:623-33.

5. Hagemann RC, Threlkeld DS, eds. Drug facts and Comparisons. $50^{\text {th }}$ ed. St Louis, MO: Wolters Kluwer Co; 1996:1862-876.

6. Coffin MD, Parr AF, inventors; Glaxo Inc., assignee. Ranitidine solid dosage form. United States Patent 5407687. 1995.

7. Kortejarvi H, Yliperttula M, Dressman JB, Junginger HE, Midha KK, Shah VP, et al. Biowaiver monographs for immediate release solid oral dosage forms: Ranitidine hydrochloride. J Pharm Sci 2005;94:1617-25.

8. Basit A, Lacey L. Colonic metabolism of ranitidine: Implications for its delivery and absorption. Int J Pharm 2001;227:157-65.

9. Dave BS, Amin AF, Patel MM. Gastroretentive drug delivery system of ranitidine hydrochloride: Formulation and in-vitro evaluation. AAPS PharmSciTech 2004;5:Article 34

10. Kaza R, Usharani E, Nagaraju R, Haribabu R, Reddy PV. Design and evaluation of sustained release floating tablets for the treatment of gastric ulcers. J Pharm Sci Res 2009;1:81-7.

11. Khemariya P, Mishra S, Shukla A, Bhargava M, Singhai K, Goswami S. An emerging trend in tablet technology: Floating tablets of ranitidine $\mathrm{HCl}$. Int J Drug Deliv 2010;2:154-8.

12. Choudhary A, Das S, Bahadur S, Saha S. Development and characterization of extended release gastroretentive drug delivery. J Pharm Res 2009;2:1557-60.

13. Gusler G, Berner B, Chau M, Padua A, inventors; DepoMed Inc., assignee. Optimal polymer mixtures for gastric retentive tablets. United States Patent 6723340. 2004 Apr 20.

14. Tiwari SB, Siahboomi AR. Applications of complementary polymers in HPMC hydrophilic extended release matrices. Drug Del Technol 2009;9:20-7.

15. Roy P, Shahiwala A. Statistical optimization of Ranitidine Hydrochloride floating pulsatile delivery system for chronotherapy of nocturnal acid breakthrough. Eur J Pharm Sci 2009;37:363-9.

16. Dash S, Murthy PN, Nath L, Chowdhury P. Kinetic modelling on drug release from controlled drug delivery systems. Acta Pol Pharm 2010;67:217-23.

17. Gambhire MN, Ambade KW, Kurmi SD, Kadam VJ, Jadhav KR. Development and in vitro evaluation of an oral floating matrix tablet formulation of diltiazem hydrochloride. AAPS PharmSciTech 2007;8:E73.

18. Chen YH, Yaung JF. Alka Seltzer fizzing- determination of percent by mass of sodium bicarbonate in alka seltzer tablets. J Chem Ed 2002;79:848-50.

19. Enayatifard R, Saeedi M, Akbari J, Tabatabaee YH. Effect of hydroxypropyl methylcellulose and ethyl cellulose content on release profile and kinetics of diltiazem HCl from matrices. Trop J Pharm Res 2009;8:425-32.

20. Dhawan S, Varma M, Sinha VR. High molecular weight poly(ethylene oxide) - based drug delivery systems Part I: Hydrogels and hydrophilic matrix systems. Pharm Technol 2005;29:72-9.

21. Kumar R. Development and in vitro evaluation of sustained release floating matrix tablets of metformin hydrochloride. Int J Pharm Sci Res 2010;1:96-101

22. Prajapati ST, Patel LD, Patel LN. Floating matrix tablets of domperidone: Formulation and optimization using simplex lattice design. Thai J Pharm Sci 2009;33:113-22.

23. Li H, Hardy JH, Gu X. Effect of drug solubility on polymer hydration and drug dissolution from polyethylene (PEO) matrix tablets. AAPS PharmSciTech 2008;9:437-43.

24. Algin E, Kilicarslan M, Karatas A, Yuksel N, Baykara T. Effects of polymer type, polymer: Direct tabletting agent ratio and tabletting method on Verapamil hydrochloride extended release from hydroxypropylmethylcellulose matrix tablets. J Fac Pharm Ankara 2004;33:125-37.

25. Rao MR, Sonar GS, Mandsaurwale RR, Vanshiv SD. Evaluation of effervescent floating matrix tablet formulations of salbutamol sulfate using full factorial design. Asian J Pharm 2009;3:43-9.

26. Thapa P, Stevans HN, Baillie AJ. In vitro drug release studies from a novel lyophilised nasal dosage forms. Kathmandu University J Sci Tech 2009;5:71-86.

27. Fukuda M, Peppas NA, McGinity JW. Floating hot- melt extruded tablets for gastroretentive controlled drug release systems. J Control Release 2006;115:121-9.

28. Lundberg PJ, Thune M. Inventors; AstraZeneca AB, assignee. Multiple unit effervescent dosage form. United States Patent, 6284271; 2001 Sep 4.

29. Hernandez BL, Leon AH, Robles LV. Effect of stearic acid on the properties of metronidazole/methocel K4M floating matrices. Braz J Pharm Sci 2009;45:497-505.

30. Chivate A, Muley V, Poddar SS. Sustained release multiparticulates via powder coating. Iranian J Pharm Res 2007;6:225-30.

31. Stamm A, Tritsch JC. Some considerations on the liberation of drugs from inert matrices. Drug Dev Ind Pharm 1986;12:2337-53.

32. Tabandeh H, Mortazavi SA, Guilani TB. Preparation of sustained- release matrix tablets of aspirin with ethylcellulose, eudragit RS100 and eudragit S100 and studying the release profiles and their sensitivity to tablet hardness. Iranian J Pharm Res 2003;2:201-6.

How to cite this article: Gharti KP, Thapa P, Budhathoki U, Bhargava A. Formulation and in vitro evaluation of floating tablets of hydroxypropyl methylcellulose and polyethylene oxide using ranitidine hydrochloride as a model drug. J Young Pharmacists 2012;4:201-8.

Source of Support: Nil, Conflict of Interest: None declared. $\square$ 